\title{
A new genus and two new species of Neotropical Myodochini (Hemiptera: Heteroptera: Rhyparochromidae)
}

\section{Un género y dos especies nuevos de Myodochini neotropicales (Hemiptera: Heteroptera: Rhyparochromidae)}

\author{
Pablo M. Dellapé \\ División Entomología, Facultad de Ciencias Naturales y Museo, Consejo Nacional de Investigaciones Cientificas y Técnicas (CONICET). Universidad \\ Nacional de La Plata, Paseo del Bosque, B1900FWA La Plata, Argentina. \\ $\checkmark$ pdellape@fcnym.unlp.edu.ar
}

\begin{abstract}
A new genus and 2 new species of Neotropical myodochines are described from Trinidad and Tobago, and Peru. Each species is diagnosed and described, and adult photographs and illustrations of the male genitalia are provided to facilitate identification. The studied specimens are deposited in the American Museum of Natural History (AMNH, New York, USA), and Museo de La Plata (MLP, La Plata, Argentina).
\end{abstract}

Key words: Myodacanthus trinidadensis, M. williamsi, Peru, Trinidad and Tobago.

Resumen. Se describe un género nuevo y 2 especies nuevas de Myodochini neotropicales de Trinidad y Tobago y de Perú. Se proporciona una diagnosis y la descripción de cada especie y se muestran fotografías de los adultos e ilustraciones de los genitales masculinos para facilitar su identificación. Los ejemplares estudiados están depositados en el American Museum of Natural History (AMNH, New York, USA) y en el Museo de La Plata (MLP, La Plata, Argentina).

Palabras clave: Myodacanthus trinidadensis, M. williamsi, Perú, Trinidad y Tobago.

\section{Introduction}

Myodochini are the most diverse tribe of Rhyparochromidae, the largest family of Lygaeoidea, in the Neotropical region. During the last decade, several new taxa have been described from Central and South America (Cervantes and Pacheco, 2003; Dellapé, 2003, 2008a, b, 2010; Cervantes, 2004, 2005; Dellapé and Melo, 2004, 2005, 2008; Cervantes and Gámez-Virués, 2005; Dellapé and Coscarón, 2005; Dellapé and Montemayor, 2008, 2011; Dellapé and Henry, 2010; Brailovsky and Cervantes, 2011), and many remain undescribed in the most important collections of the world. Members of the tribe are generally found on the ground, living in litter below plants, although some arboreal taxa are also known (Cervantes and Pacheco, 2003, Dellapé and Henry, 2010; Dellapé and Montemayor, 2011).

In this contribution, a new genus and 2 new species of myodochines from Trinidad and Tobago, and Peru are described. Each species is diagnosed and described; adult photographs and illustrations of male genitalia are provided to facilitate identification.

Recibido: 09 mayo de 2011; aceptado: 29 junio de 2011

\section{Materials and methods}

Acronyms used for institutions cited in the paper are AMNH (American Museum of Natural History, New York, USA) and MLP (Museo de La Plata, La Plata, Argentina). Measurements are given in millimeters.

\section{Descriptions}

Myodacanthus gen. nov.

Type species: Myodacanthus trinidadensis Dellapé, sp. nov.

Diagnosis. Pruinose. Vertex flattened; juga rounded; postocular distance slightly shorter than interocellar space; pygophore: anterior margin of dorsal aperture with small denticles; aedeagus: conjunctiva with large spines, vesica with lobes ending in stout spines, and gonoporal process thin and long.

Description. Pilose. Head slightly elongate behind eyes, forming a short neck; vertex flattened, buccular juncture V-shaped close to rostral insertion; eyes oval; juga rounded. Pronotum punctate, with punctures slightly larger on posterior pronotal lobe; lateral margins of both pronotal lobes rounded; collar well delimited, but without a posterior sulci; anterior pronotal lobe pruinose 
except for shiny shagreened irregular patches, posterior pronotal lobe pruinose. Scutellum and hemelytra pruinose. Hemelytra with small well defined punctures. Clavus with 3 rows of punctures, and a partial fourth between inner and median rows on distal three-quarters. Evaporative area extensive, covering all of metapleural area, except dorsal one quarter or less; mesepimeron emergent to enclosed. Procoxa with 1 spine; protrochanter unarmed; profemur incrassate, with 2 rows of spines on distal half filled in between with minute spines; protibia straight, with numerous minute tubercles over entire ventral surface; male mesofemur unarmed. Pygophore: anterior margin of dorsal aperture with small denticles. Aedeagus: Conjunctiva with large spines, vesica with lobes ending in stout spines, gonoporal process thin and long.

Etymology. The generic name is based on the prefix "myod" for the tribal name Myodochini and the Greek word akanthos, meaning spinose. Gender masculine.

Remarks. Myodacanthus runs to couplet 34 in Harrington's (1980) key to the Myodochini of the world, where the genus Pamerana is identified. Pamerana Distant is an Oriental and Palearctic genus whose species have the posterior edge of the pygophore with a marked deep median groove and an unspined aedeagus. The morphology of the male genitalia relates the species of Myodacanthus to Catenes australis Dellapé and Melo, 2008. After Harrington's analysis Catenes Distant was related with the long-legged rapid running forms including Heraeus Stål, Myodocha Latrielle and Orthaea Dallas, but Dellapé and Melo (2008) stated that the spined aedeagus of Catenes australis separates Catenes from this group and the phylogenetic relationships of the genus remain uncertain.

The condition of the mesepimeron, emergent or enclosed, between the mesepisternum and metepisternum is generally constant among the species of any genera in Myodochini, but in this case the only specimen known of Myodacanthus williamsi n. sp. shows a mesepimeron emergent and the specimens of Myodacanthus trinidadensis n. sp. show a variable condition from a mesepimeron barely emergent to a mesepimeron clearly enclosed. Several characters from the external morphology and male genitalia allowed considering both species cogeneric.

Myodacanthus trinidadensis sp. nov. (Figs. 1, 2a-j) Diagnosis. Antenna elongate, pedicel long, longer than basiflagellomere, that is slightly widening towards apex; antenniferous tubercles slightly divergent in dorsal view; and pygophore (Figs. 2a-d) with a characteristic shape in dorsal view, with a rounded protuberance distally.

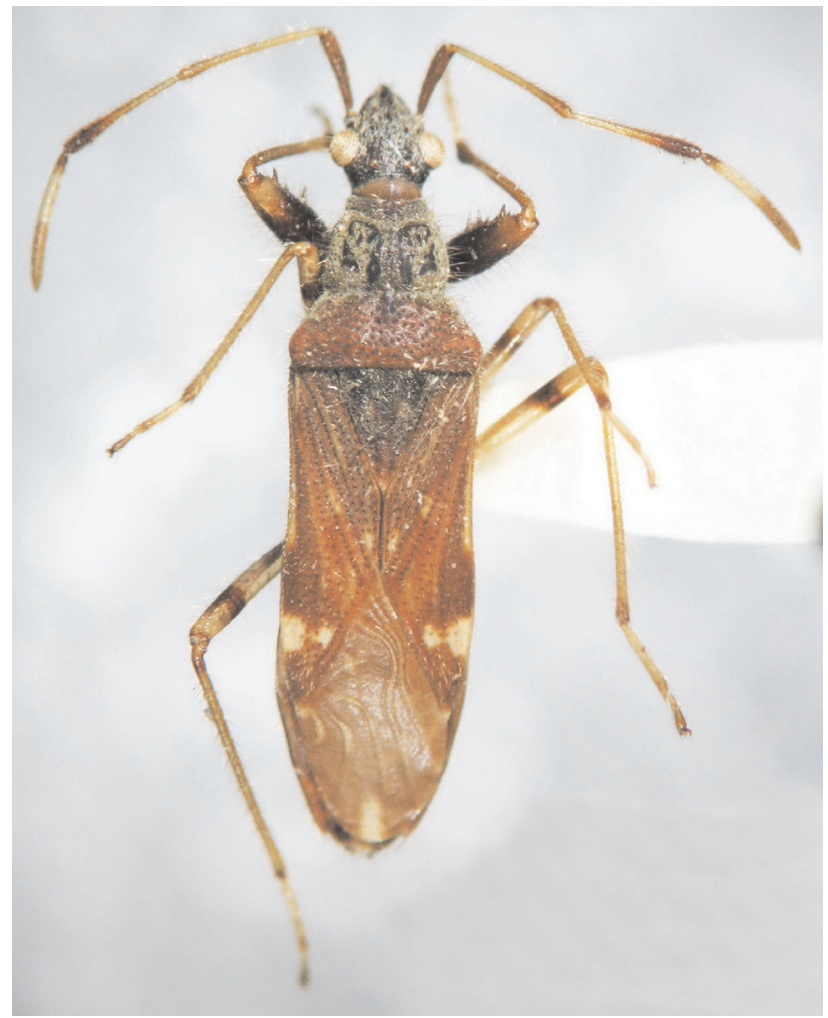

Figure 1. Myodacanthus trinidadensis sp. nov.

Description. Male holotype (Fig. 1). Total length: 8.13. Head black; with abundant short, decumbent, silvery setae, and long erect setae. Head length: 1.29; width: 1.23; anteocular length 0.64 ; postocular length 0.24 . Antenniferous tubercles slightly divergent in dorsal view. Interocular space: 0.63 . Eyes with long setae between ommatidea. Ocelli located behind posterior margin of eyes, closer to collar than to eyes. Interocellar space: 0.31 . Rostrum surpassing procoxae, segment I and II light brown, III and IV darker; with sparse semierect setae. Rostral segment lengths: I 0.75; II 0.83, III 0.59; IV 0.43. Antenna: scape, pedicel and basiflagellomere distally, and distiflagellomere brown; rest of pedicel and basiflagellomere light brown; distiflagellomere with a subbasal yellowish band about one third of segment length; scape stout, basiflagellomere slightly widening towards apex; with abundant short decumbent setae, and erect setae longer on pedicel and basiflagellomere. Antennal lengths: scape 0.95; pedicel 1.90; basiflagellomere 1.60; distiflagellomere 1.70.

Anterior pronotal lobe black; posterior pronotal lobe dark brown; humeral angles pale brown laterally; pronotal disk and scutellum with abundant short, decumbent and semierect, silvery setae, and long erect setae, shorter on posterior pronotal lobe. Collar length 0.18 ; anterior 
lobe length 0.95 ; posterior lobe length 0.75 . Collar width 0.85 ; anterior lobe width 1.43 ; posterior lobe width 2.15 . Scutellum dark brown, paler towards apex. Hemelytra brown, with abundant short erect setae, slightly shorter than those on posterior pronotal lobe. Clavus brown, except for a rounded pale brown macula subapically on outer margin. Corium brown, except anterior two-thirds of lateral margins, a small rounded macula medially, and a subapical irregular macula pale yellowish; outer margin of corium slightly concave and crenulate on anterior two-thirds. Membrane fuscous, with a small macula adjacent to apex of corium, veins partially and a small subapical macula whitish. Mesepimeron barely emergent. Pleura black, punctate, with abundant short, decumbent or semierect, silvery setae. Legs: coxae, protrochanters, profemora (except distally), a subapical band of meso- and metafemora dark brown; apex of meso- and metafemora, base of tibiae, tarsi distally and pretarsi infuscated with brown; rest of legs light brown. Legs with abundant, semierect and erect silvery
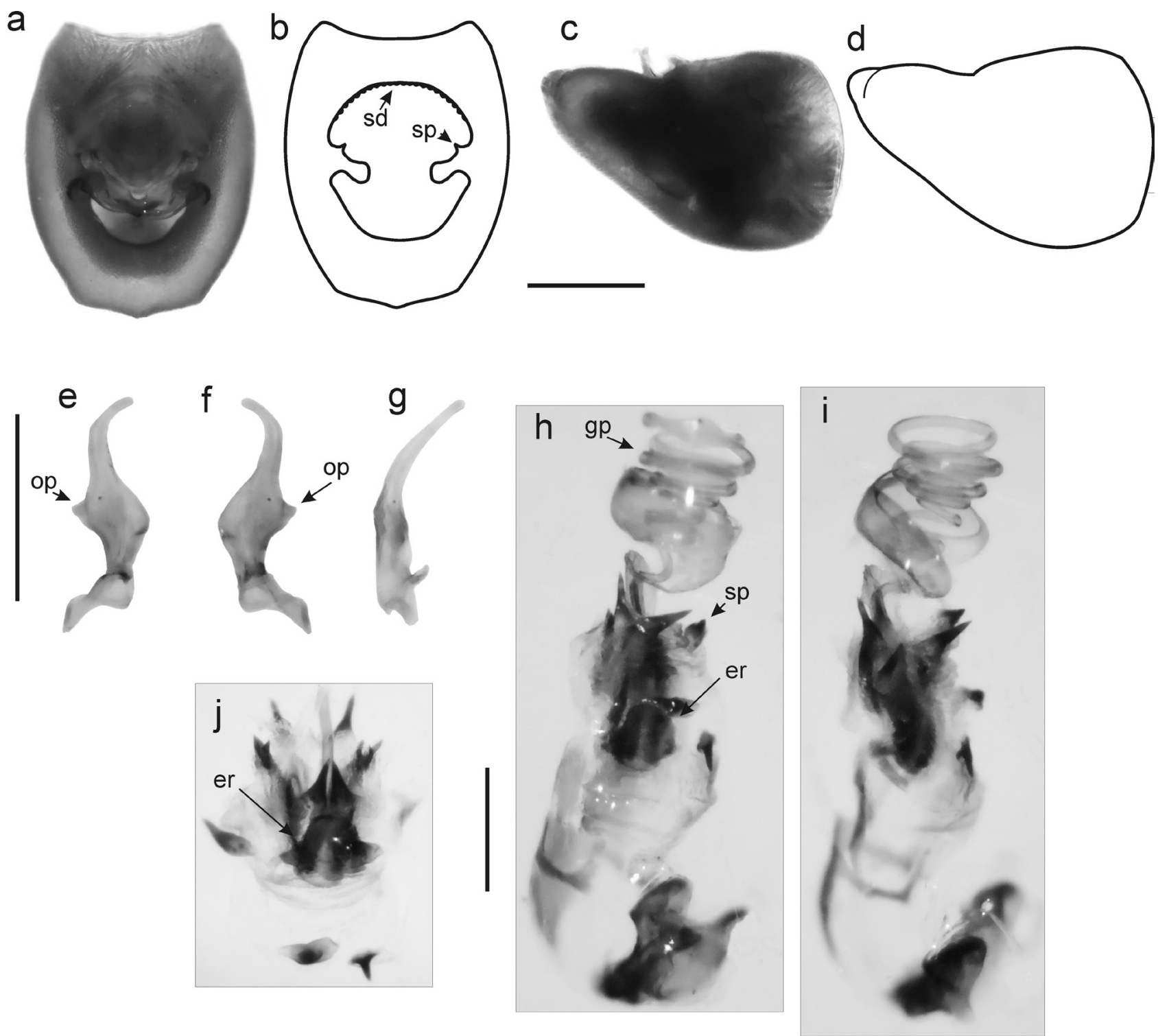

Figure 2. Myodacanthus trinidadensis sp. nov. Male genitalia: (a-d) pygophore: (a), dorsal view; (b), schematic drawing of dorsal view; (c), lateral view; (d), schematic drawing of lateral view. (e-g) right paramere: (e), inner view; (f), outer view; (g), posterior view. (h-j) aedeagus: (h), anterior view; (i), lateral view; (j), detail of ejaculatory reservoir and spines, anterior view. Abbreviations, er: ejaculatory reservoir; gp: gonoporal process; op: outer projection; sd: small denticles on anterior margin of dorsal aperture; sp: spine. Scale line $0.5 \mathrm{~mm}$. 
setae, longer on profemora. Abdomen brown, with abundant short decumbent silvery setae, and sparsely long erect setae. Male genitalia: pygophore (Figs. 2a-d): characteristic shape in dorsal view, anterior margin of dorsal aperture rounded with small denticles, with a small spine before inner projections which are long and digitiform; in lateral view, elongate with dorsal margin horizontal (Figs. 2c, d). Parameres (Figs. 2e-g): blade curved, outer projection thumb-like, relatively small. Aedeagus (Figs. h-j): conjunctiva with 2 large spines anteriorly, vesica with partially sclerotized lobes ending in a stout spine.

Female. Similar to male in all aspects.

Measurements of male and female paratypes (measurements: range [ $\mathrm{n}=5$ $\uparrow \mathrm{8}$ \%], followed by mean): total length $7.88-8.13,8.04 ; 8.00-8.50,8.17$. Head: length $1.21-1.31,1.25 ; 1.25-1.42,1.35$; width 1.14-1.19, 1.17 ; 1.20-1.32, 1.26; anteocular distance 0.63-0.65, $0.64 ; 0.63-0.68,0.66$; postocular distance $0.21-0.23$, $0.22 ; 0.19-0.24,0.21$; interocular space $0.56-0.60,0.59$; $0.63-0.66,0.64$; interocellar space $0.25-0.31,0.29$; $0.31-0.34,0.32$. Antennal lengths: scape $0.88-1.00$, 0.94 ; $0.83-0.93,0.89$; pedicel $1.73-1.93,1.83 ; 0.83-$ 0.93, 0.89; basiflagellomere $1.40-1.58,1.51 ; 1.38-1.50$, 1.44; distiflagellomere 1.63-1.78, 1.71; 1.58-1.73, 1.64 . Rostral segment lengths: I $0.75-0.81,0.78 ; 0.71-0.81$, 0.78 ; II $0.79-0.83,0.81 ; 0.81-0.85,0.82$; III $0.55-0.56$, $0.55 ; 0.56-0.59,0.58 ;$ IV $0.40-0.45,0.43 ; 0.44-0.48$, 0.46. Collar length $0.15-0.19,0.17 ; 0.19-0.20,0.19$; anterior lobe length $0.81-0.89,0.86 ; 0.75-0.84,0.81$; posterior lobe length $0.65-0.75,0.72 ; 0.75-0.85,0.79$. Collar width 0.81-0.88, 0.85; 0.85-0.93, 0.89; anterior lobe width $1.25-1.60,1.37 ; 1.30-1.45,1.37$; posterior lobe width $1.88-2.05,1.98 ; 2.00-2.23,2.14$.

Material examined. Holotype: Trinidad, Simla, 1965, light trap, M. Emsley (AMNH). Paratypes: 5 ${ }^{\lambda} 7$ ㅇ, same data (AMNH); 1 +, Trinidad: Simla, Arima, Blanchisseuse Rd., elev. 600 ft., 20-VII-75, blacklight trap, J. Price (AMNH); 1 s/a, Trinidad, B.W.I., Arima Valley 27-V-1952, Gift of New York Zoo. Soc., Dept. Tropical Research William Beebe Dir., Neopamera sp. Det Harrington 1981 (AMNH).

Etymology. The epithet refers to the West Indies island where the specimens were collected.

Distribution. Trinidad and Tobago (Trinidad Island).

Myodacanthus williamsi sp. nov. (Figs. 3, 4a-i)

Diagnosis. Antennae with a relatively short pedicel, shorter than distiflagellomere; basiflagellomere widening towards apex; antenniferous tubercles parallel in dorsal view; and pygophore (Figs. 4a-d) subtriangular in dorsal view, produced posteriorly.

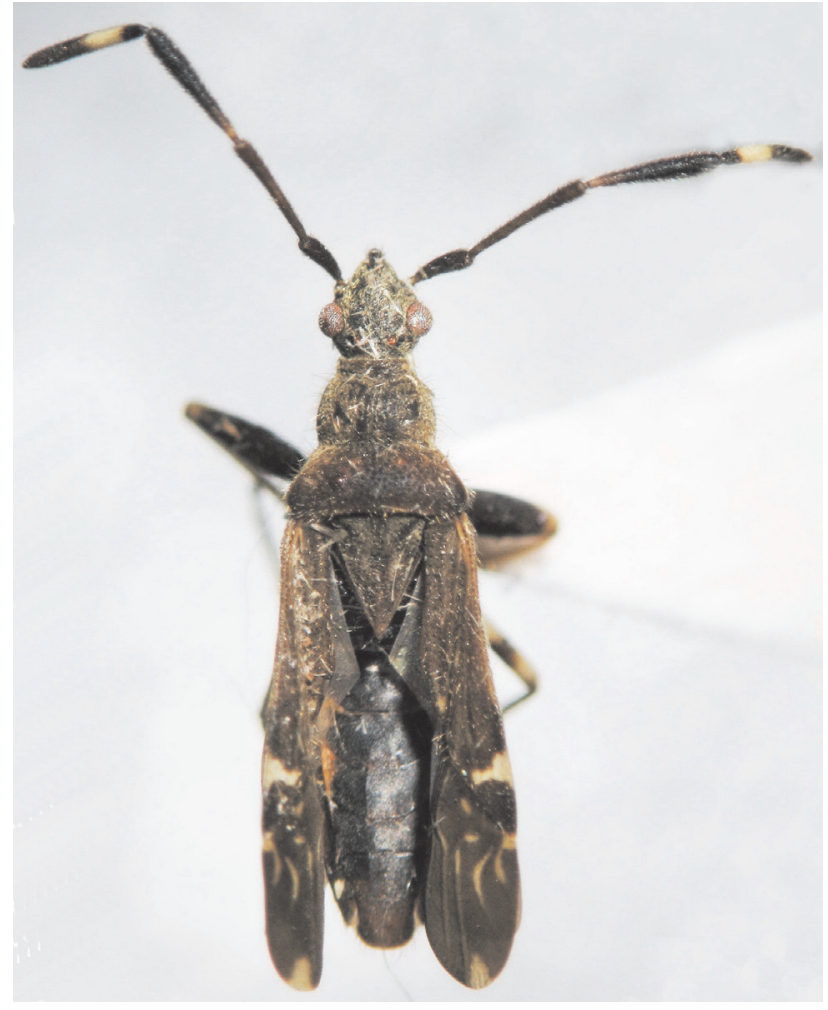

Figure 3. Myodacanthus williamsi sp. nov.

Description. Male holotype (Fig. 3). Total length: 7.25. Head black; with abundant short decumbent silvery setae, and long erect setae dorsally. Head length: 1.19; width: 1.19; anteocular length 0.60 ; postocular length 0.25 . Antenniferous tubercles parallel in dorsal view. Interocular space: 0.63 . Eyes with long setae between ommatidea. Ocelli located behind posterior margin of eyes, closer to collar than eyes. Interocellar space: 0.26 . Rostrum surpassing procoxae, segment I and II light brown, III and IV darker; with sparse semierect setae. Rostral segment lengths: I 0.65; II 0.69, III and IV embedded in glue. Antenna: scape brown, pedicel and basiflagellomere basally light brown; rest of basiflagellomere and distiflagellomere dark brown; distiflagellomere with a subbasal contrasting yellowish band about one third of segment length; scape stout, basiflagellomere widening towards apex; with abundant short decumbent setae, and scattered erect setae more abundant on scape and pedicel. Antennal lengths: scape 0.78; pedicel 1.58; basiflagellomere 1.40; distiflagellomere 1.63. Anterior pronotal lobe black, posterior pronotal lobe dark brown with irregular paler areas anteriorly, humeral angles pale brown laterally; pronotal disk and scutellum with abundant short decumbent and semierect, silvery setae, and long erect setae, shorter on posterior pronotal lobe. Collar length 0.19 ; anterior lobe length 0.71 ; posterior 
lobe length 0.73 . Collar width 0.81 ; anterior lobe width 1.24; posterior lobe width 2.43. Scutellum dark brown. Hemelytra dark brown, with short decumbent and semierect setae. Clavus dark brown, except for a rounded pale brown maculae subapically on outer margin. Corium dark brown, except anteriorly, on lateral margins of anterior twothirds, a small rounded macula medially, and a subapical irregular macula pale yellowish; outer margin of corium slightly concave and irregularly crenulate on anterior two-thirds. Membrane dark, fuscous, with a basal macula, veins partially and a small subapical macula contrastingly whitish. Mesepimeron emergent. Pleura black, punctate, with abundant short decumbent silvery setae. Legs: coxae, protrochanters, profemora (except distally), a subapical band and apex of meso- and metafemora, tibiae and tarsi distally, and pretarsi dark brown; base of tibiae infuscated with brown, rest of legs light brown. Legs with semierect and erect silvery setae, longer on profemora. Abdomen brown, with abundant short decumbent silvery setae, and sparsely long erect setae. Male genitalia: pygophore (Figs. 4a, d): subtriangular in dorsal view, produced posteriorly, anterior margin of dorsal aperture rounded, strongly sclerotized, with small denticles and adjacent area strongly sclerotized; with a small spine before inner projections
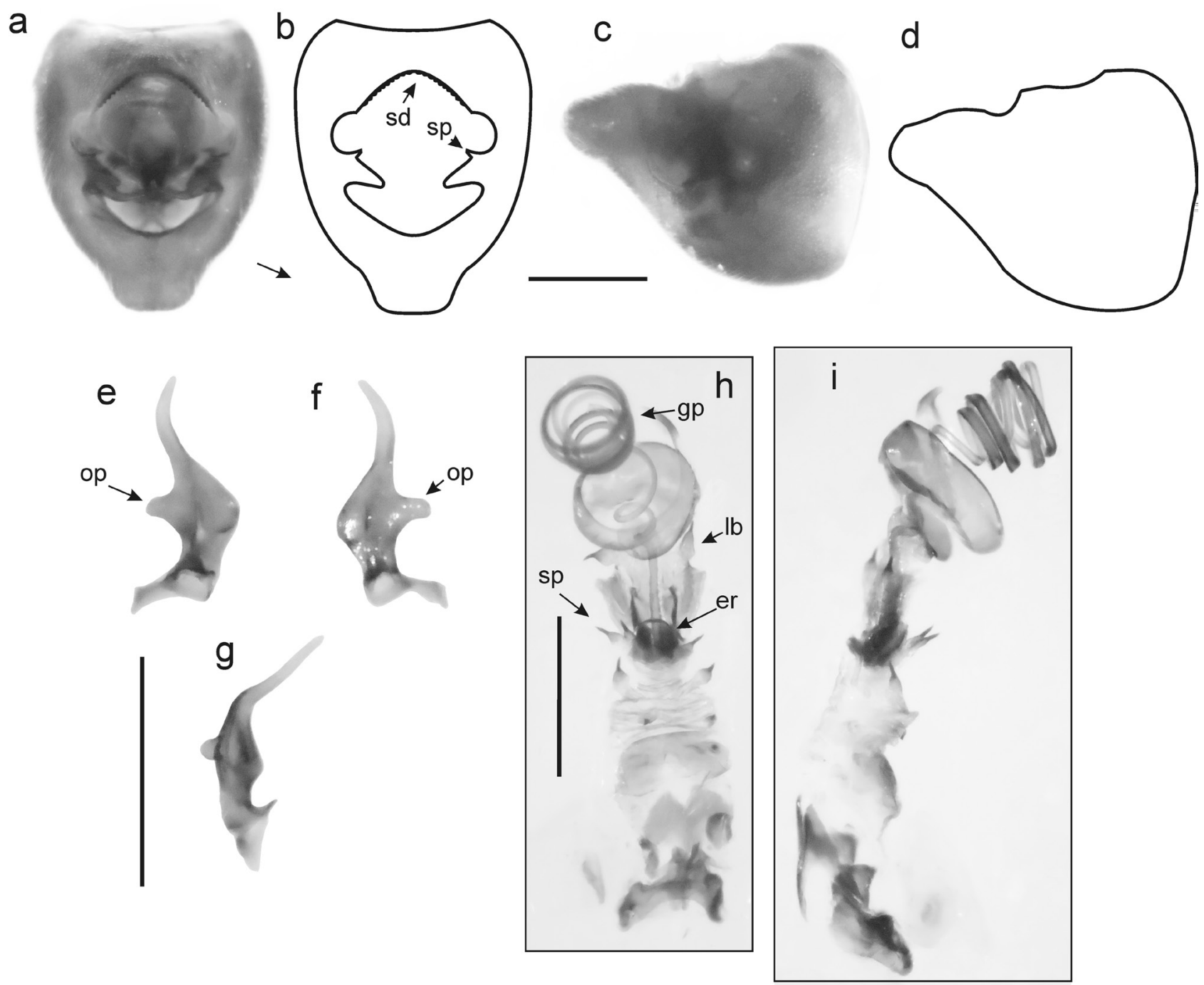

Figure 4. Myodacanthus williamsi sp. nov. Male genitalia: (a,d) pygophore: (a), dorsal view; (b), schematic drawing of dorsal view; (c), lateral view; (d), schematic drawing of lateral view. (e-g) right paramere: (e), inner view; (f), outer view; (g), posterior view. (h-i) aedeagus: (h), anterior view; (i), lateral view. Abbreviations, er: ejaculatory reservoir; gp: gonoporal process; lb: lobe; op: outer projection; sd: small denticles on anterior margin of dorsal aperture; sp: spine. Scale line $0.5 \mathrm{~mm}$. 
long and digitiform; in lateral view, as in figure 4c-d. Parameres (Figs. 4e-g): blade curved, outer projection blunt. Aedeagus (Figs. 4h, i): conjunctiva with few large spines, vesica with sclerotized lobes ending in a stout spine.

Material examined. Holotype ${ }^{\lambda}$, Peru, Cusco, San Martín 2, Base Pluspetrol, $72^{\circ} 46^{\prime} 53^{\prime \prime} \mathrm{W}, 1^{\circ} 46^{\prime} 17^{\prime}$ S, luz, II-[20]06, J. Williams (MLP).

Etymology. This species is named after my friend, the herpetologist Prof. Jorge Williams (MLP), who kindly collects insects using light traps during his field trips.

Distribution. Peru.

Remarks. This species is similar in general appearance and coloration pattern to M. trinidadensis. The shorter and stout antenna, with a relatively short pedicel, shorter than distiflagellomere, the basiflagellomere strongly widening towards apex, and the subtriangular pygophore, produced posteriorly are the more conspicuous characters to identify this species. Besides M. williamsi exhibit the antennae with shorter and more abundant pilosity, and shorter and less abundant setae on legs. The only specimen known of $M$. williamsi exhibit a more contrasting pattern coloration that the studied specimens of M. trinidaensis.

\section{Acknowledgments}

I thank Randall T. Schuh (AMNH) for the loan of the specimens of $M$. trinidadensis; María Cecilia Melo (Instituto de Limnología "Dr. Raúl A. Ringuelet") for the critical reading of the manuscript, and the Division Zoología Invertebrados (MLP) for providing the photographic equipment used. Finally, I thank CONICET (Consejo Nacional de Investigaciones Científicas y Técnicas, Argentina) for the financial support.

\section{Literature cited}

Brailovsky, H. and L. Cervantes-Peredo. 2011. New genus, new species and new records of Mexican Lygaeoidea (Hemiptera: Heteroptera). Studies on Neotropical Fauna and Environment 46:197-201.

Cervantes, P. L. 2004. Cholula minuta, a new species of Myodochini (Lygaeoidea: Rhyparochromidae) from Jamaica. Florida Entomologist 87:173-175.

Cervantes, P. L. 2005. Two new species of Myodocha (Lygaeoidea: Rhyparochromidae: Myodochini) with a key to species. Annals of the Entomological Society of America 98:458-469.

Cervantes, P. L. and S. Gámez-Virués. 2005. Three species of facultative Myodochini (Lygaeoidea: Rhyparochromidae) associated with figs in Mexico. Proceedings of the Entomological Society of Washington 107:362-375.
Cervantes, P. L. and I. Pacheco. 2003. Biology and description of a new species of Cholula (Heteroptera: Rhyparochromidae: Myodochini) associated with a fig in México. Journal of the New York Entomological Society111:41-47.

Dellapé, P. M. 2003. A new species of Ashlockobius (Heteroptera: Rhyparochromidae: Myodochini) from Venezuela. Zootaxa 289:1-6.

Dellapé, P. M. 2008a. Bergicoris, a new genus for Neotropical species previously placed in Cnemodus Herrich-Schaeffer, and a new species from Argentina (Heteroptera: Lygaeoidea: Rhyparochromidae). Deutsche Entomologische Zeitschrift 55:101-107.

Dellapé, P. M. 2008b. Paisana: A new genus of Neotropical Rhyparochromidae (Hemiptera: Heteroptera) to accommodate Neopamera brachialis (Stål) and four new species. Zootaxa 1958:17-30.

Dellapé, P. M. 2010. Designation of type species for Bergicoris. Deutsche Entomologische Zeitschrift 57:275.

Dellapé, P. M. y M. C. Coscarón. 2005. Redescription of Pseudoparomius linearis Stål, and description of three new species of Pseudoparomius Harrington (Rhyparochromidae: Heteroptera). Zootaxa 909:1-12.

Dellapé, P. M. and T. J. Henry. 2010. A new genus and two new species of Myodochini (Hemiptera: Heteroptera: Rhyparochromidae) from canopy of Ecuador and Peru. Insect Systematics and Evolution 41:75-89.

Dellapé, P. M. and M. C. Melo. 2004. A new species of Erlacda Signoret (Heteroptera: Lygaeoidea: Rhyparochromidae) from Argentina. Studies on Neotropical Fauna and Environment 39:201-205.

Dellapé, P. M. and M. C. Melo. 2005. Dushinckanus n. sp., a new mirmecomorphic rhyparochromid from Argentina (Insecta: Heteroptera: Lygaeoidea). Zootaxa 901:1-6.

Dellapé, P. M. and M. C. Melo. 2008. A new species of Catenes Distant from South America (Rhyparochromidae: Myodochini). Deutsche Entomologische Zeitschrift 55:245248.

Dellapé, P. M. and S. I. Montemayor. 2008. A revision of the genus Orthaea Dallas (Rhyparochromidae: Heteroptera), with the description of two new species and a new genus: Neomyocoris, to accommodate $O$. arnaudi Brailovsky. Studies on Neotropical Fauna and Environment 43:147-157.

Dellapé, P. M. and S. I. Montemayor. 2011. On the identity of Ashlockobius Slater and Slater and Villalobosothignus Brailovsky (Hemiptera: Heteroptera: Rhyparochromidae: Myodochini), with the description of a new arboreal species from Ecuador. Zootaxa 2748:47-52.

Harrington, B. J. 1980. A generic level revision and cladistic analysis of the Myodochini of the world (Hemiptera, Lygaeidae, Rhyparochrominae). Bulletin of the American Museum of Natural History 167:49-116. 